\title{
Electrical conductivity of Self-assembling Peptide-semiconducting dye Conjugate nanofibre networks
}

Zainab O. Makinde ${ }^{a, b}$, Aakanksha Rani ${ }^{b, c}$, Taniela Lolohea ${ }^{a, b}$, Laura J. Domigan ${ }^{\text {b,d }}$, Duncan J. McGillivray a,b, Margaret Brimble ${ }^{a, b}$, and David E. Williams ${ }^{a, b *}$

a. School of Chemical Sciences, The University of Auckland, 23 Symonds St., Auckland 1010, New Zealand.

b. MacDiarmid Institute for Advanced Materials and Nanotechnology, Victoria University of Wellington, Wellington 6140, New Zealand.

c. School of Biological Sciences, The University of Auckland, 3A Symonds St., Auckland 1010, New Zealand.

d. Department of Chemical and Materials Engineering, The University of Auckland, 20 Symonds St., Auckland 1010, New Zealand.

*E-mail: david.williams@auckland.ac.nz

\begin{abstract}
Conjugates comprising a semiconducting dye (Thiophene-diketopyrrolopyrrole, TDPP-dye) attached to a self-assembling peptide (HEFISTAH) assemble into long nanofibers. Wellordered Langmuir-Blodgett films of these materials can be prepared. Networks of these nanofibres can be deposited to bridge electrodes. Although similar systems have been proposed as organic semiconductors, in this case, no electronic conductivity was observed. Instead, the fibres behaved as ionic (probably proton) conductors as a consequence of adsorbed water. A strong dependence of electrical conductivity on relative humidity and fibre network density was demonstrated. The system of nanofibers bridging gold electrodes behaved as an electrolytic cell, with oxygen reduction as a limiting electrode reaction.
\end{abstract}

\section{Introduction}

The limitations posed by conventional semiconductive materials concerning health and environmental applications have led to continuous interest in the design of semiconductors that are biocompatible and environmentally friendly. Self-assembled nanostructures featuring short peptides are suitable candidates for the development of semiconducting materials that may bridge the gap between conventional semiconductors and biological systems [1]. 
Potential applications of self-assembling peptides, based on their ease of synthesis, ease, and range of accessible chemical modification, and geometrical precision have been wellrehearsed in several reviews [2-8]. Their ability to form different nanostructures such as tapes, ribbons, fibres, and vesicles through intermolecular interactions makes them particularly interesting. Their ease of modification is also an attractive property that enables their functionalization or conjugation with a vast range of other functional molecules. One such possibility is conjugation with a candidate molecule for an organic semiconductor, the idea being that the peptide could promote the assembly of a semiconducting fibril.

In designing organic semiconductors, small molecules and polymers containing heteroaromatic backbones have been of increasing interest. For this study, we have used a thiophene-diketopyrrolopyrrole (TDPP) as our semiconducting building block. TDPP is a fluorescent molecule that has been widely explored in the development of organic-based electronics such as field-effect transistors and photovoltaics [16-21]. The thermal and photostability make it appealing to use. In the solid-state, TDPP molecules show a significant orbital overlap between neighbouring molecules enabling long-range charge transport [22]. This is a result of the presence of a planar $\pi$-conjugated system and intermolecular hydrogen bond.

Another interesting property of TDPP is its ease of modification. The thiophene rings and the secondary amine groups in the TDPP have been commonly used as the synthetic point for a wide range of derivatisation [23-25]. For example, the problem of the low solubility of TDPP in organic solvents can be addressed by alkylating the amide functionalities. However, alkylating can as well alter the electronic properties of the TDPP [24, 25]. In this regard, appending selfassembly units to the core of the TDPP can be an alternative approach to increasing its solubility and improving its molecular organization while also retaining its intrinsic properties. For example, Adams et al., [26] have reported the successful attachment of phenylalanine to TDPP derivatives which resulted in a chromophoric hydrogelator with $\mathrm{pH}$-dependent conduction properties. The intriguing properties displayed by self-assembling peptides have identified them as an ideal candidate to be conjugated with heterocyclic compounds such as TDPP. While several synthetic peptides have been explored for this course, an interesting avenue for exploration is the use of natural self-assembling peptide sequences derived from natural proteins to introduce self-assembly properties on heteroaromatic polycyclics, to obtain self-assembling semiconducting materials. For example, Eakins et al., [27] have reported conjugation to a 7-amino acid peptide sequence IKHLSVN (inspired by the $\beta-\beta$ interphase of a natural protein: peroxiredoxin 3) to induce self-assembly of a perylene di-immide based semiconductor building block. 
The present work aims to explore the semiconducting properties of a new class of bio-organic material featuring a natural self-assembling octapeptide (HEFISTAH) and a semi-conducting TDPP dye. HEFISTAH is the only peptide of the already reported 4 peptides existing at the interphase of homo-oligomeric proteins that do not contain an amino acid that can complicate the regiospecific derivation of organic material. We reasoned that the conjugation of TDPP to the N-terminal of HEFISTAH would improve the solubility of the resultant material in an aqueous solution and also facilitate the formation of structured films. Conjugation of aromatic polycyclic units to peptides is known to induce the formation of fibres, so we also reasoned that TDPP attachment would not hinder but improve the self-assembling properties of the peptides. We then speculated that the resultant assembly would couple the TDPP moieties on adjacent molecules resulting in an extended semiconducting nanofibre.

The synthesis and characterization of this bio-organic material conjugate have been reported by our group, Scheme 1 [28]. The self-assembly of the HEFISTAH peptide is retained after conjugation with TDPP [29]. Herein, we report the formation and characterization of a longrange ordered $2 \mathrm{D}$ assembly of this new class of material using the Langmuir Blodgett technique. To the best of our knowledge, Langmuir films of this kind of hybrid material have never been reported. We also describe the conducting properties of the peptide-dye nanofibers. We deduce that these are proton conductors but not electronic conductors. 
(a)

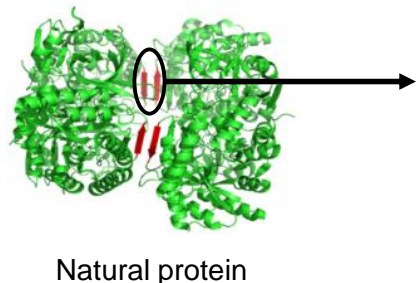

(b)

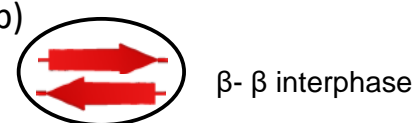

(c)

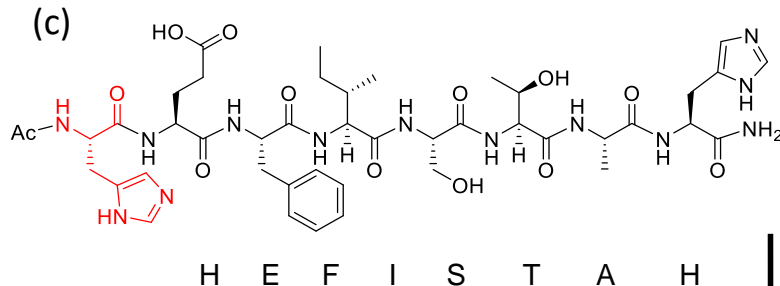

(e)

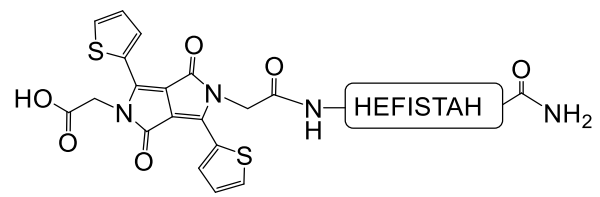

Mono-conjugated product (27\%) (d)

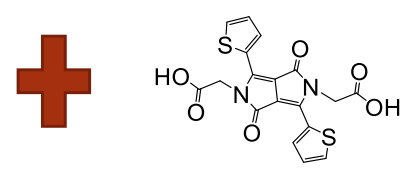

(i) PyBOP, 6-Cl-HOBt DIPEA,NMP

(ii) TFA:TIPS: $\mathrm{H}_{2} \mathrm{O}$

$(95: 2.5: 2.5)$

Scheme 1: Schematic representation of the synthesis of the new class of bio-organic material featuring a semiconducting dye and a natural self-assembling peptide. (a) Crystal structure of the natural protein, (b) HEFISTAH sequence highlighted in black (c) Peptide sequence structure (d)TDPP-thienyl N, N'-diacetic acid (e) Mono-conjugated (27\%) and (f) Di-conjugated product $(15 \%)[28,29]$.

\section{Experimental Section}

The N-terminal acetylated peptide (c) mono-conjugated product (e) and di-conjugated product (f) were prepared following the schematic protocol represented in Scheme 1. Detailed experimental and purification procedure is reported in [28] ESI 1-3 also shows the analytical HPLC and ESI-MS data of the un-conjugated peptide and the resultant peptide-dye conjugates confirming their purity. The products were water-soluble. A $1 \mathrm{wt}$ \% solution in water of either the mono- or the di-conjugate sample appears as a clear liquid, with no gel formation observed.

The Langmuir trough was the MicrotroughX from Kibron Inc., Finland. The initial area was $106.2 \mathrm{~cm}^{2}$, and the volume of the subphase was approximately $125 \mathrm{~mL}$ in all experiments. The trough was thoroughly cleaned using ethanol and Milli-Q water and dried before every use. Before spreading the peptide, the interface was vacuum cleaned by moving a tip attached 
to a vacuum setup across the surface. The surface pressure-area $(\Pi-A)$ isotherms were taken upon compression after each cleaning until a surface pressure change of less than $0.2 \mathrm{mN} / \mathrm{m}$ was achieved, indicating an uncontaminated interface. Measurements were made at room temperature $\left(20^{\circ} \mathrm{C}\right)$.

The Langmuir-Blodgett films of the mono and di-conjugated samples were formed by spreading $50 \mu \mathrm{L}$ of a $1 \mathrm{mg} / \mathrm{ml}$ solution dissolved in Milli-Q water onto the sub-phase (Milli-Q water) using a microsyringe. The system was allowed to equilibrate for approx. 15 mins and the surface pressure-area (П-A) isotherm was recorded upon compression and expansion of barriers at a constant speed of $31 \mathrm{~mm} / \mathrm{min}: 0.43 \AA^{2} / \mathrm{molecule} / \mathrm{s}$ and $0.69 \AA^{2} / \mathrm{molecule} / \mathrm{s}$ for the mono and di-conjugated samples respectively.

The LB film formed at the interphase was transferred onto a solid substrate (mica) that has been previously inserted into the sub-phase before film transfer and each LB film was achieved through upward removal of the substrate (upward stroke) at a constant speed of 5 $\mathrm{mm} / \mathrm{min}$ while keeping the pressure constant. The morphology of the films transferred onto mica was investigated using atomic force microscopy (AFM). All AFM measurements reported in this work were taken using the Cypher ES AFM in tapping mode using a silicon probe with a resonance frequency of $150 \mathrm{~Hz}$ (Tap150, Budget Sensors, Sofia, Bulgaria). ATIR-FTIR data were collected using a PerkinElmer 100 FTIR spectrometer. Each spectrum is an average of 128 scans over the range of $4000-400 \mathrm{~cm}^{-1} .1$ wt. \% of the peptide, unconjugated peptide, mono, and di-conjugated samples were prepared in water. All three solutions appear as a clear liquid and no gel was observed. Similarly, the FTIR spectrum of the LB films of mono and di-conjugated samples transferred onto mica was investigated.

Samples for electrical measurement were prepared on an interdigitated gold band microelectrode arrays (Micrux Fluidic, Spain) both by Langmuir-Blodgett deposition and by drop-casting $10 \mu \mathrm{L}$ of peptide solution and allowing the film to dry in air. The arrays comprised a $3.5 \mathrm{~mm}$ diameter disc of $10 \mu \mathrm{m}$ wide gold bands interdigitated with $10 \mu \mathrm{m}$ spacing, fabricated on a glass substrate. As a control to distinguish any specific effect of the TDPP conjugate, the unconjugated self-assembling peptide HEFISTAH was used. Electrical measurements used an Emstat Pico Potentiostat (Palmsens, Netherlands). DC current-potential difference measurements were performed using a staircase with amplitude $20 \mathrm{mV}$ over the range 0 to 2 $\checkmark$ potential difference applied between the electrodes. AC impedance was measured over the frequency range of $20 \mathrm{~Hz}$ to $2 \mathrm{MHz}$ using an AC perturbation voltage of $250 \mathrm{mV}$ and a DC bias voltage of $0 \mathrm{~V}$. Measurements were performed in a glass chamber placed in a Faraday cage at room temperature $\left(20 \pm 1^{\circ} \mathrm{C}\right)$. The atmosphere for the measurement was varied in water vapour pressure and oxygen partial pressure: dried, humidified, or ambient room air; dried or humidified nitrogen; and partial vacuum. Ambient air had a relative humidity of $59 \%$, 
and the laboratory piped vacuum had a pressure of approximately 46 torr. Nitrogen had an oxygen content of $<0.1 \%$. Gases were dried by passage through a column of $4 \AA$ molecular sieves or humidified by bubbling through pure water at room temperature.

\section{Results and Discussion}

To understand the structural and morphological properties of the self-assembling peptide and its mono and di conjugated samples, FTIR and Atomic Force Microscopy were used to investigate the secondary structures and structural morphologies of the samples. The FTIR spectrum of a 1 wt. \% aqueous solution of the peptide and the conjugates, Figure 1(a), had a broad band between $1600 \mathrm{~cm}^{-1}$ and $1700 \mathrm{~cm}^{-1}$ indicating the presence of $\alpha$-helix, $\beta$-sheet, and possibly random coil secondary structures. The spectra indicate that the mono- and diconjugated samples retained the intrinsic secondary structure of the peptide.

AFM of the film formed from drop-casting a 1 wt. \% aqueous solution of the unconjugated peptide on freshly cleaved mica and imaged in air revealed fibrils with a width of $~ 54 \pm 5 \mathrm{~nm}$, Figure 1 ((b) - (d)). However, for the mono and di-conjugated samples, an extended network of fibre nanostructures was observed. The width of fibres $~ 94 \pm 5 \mathrm{~nm}$ observed for the monoconjugated sample was almost double the width of those from the self-assembling peptide (HEFISTAH) alone and wider than the observed width for the di-conjugated sample $(\sim 74 \pm 5$ $\mathrm{nm})$. A longer length of the extended network of fibres was observed in the di-conjugated sample compared to the mono-conjugated sample. The absence of an extended network of fibres in the HEFISTAH peptide sample indicates that conjugation with the TDPP dye enhances the formation of an extended network of self-assembled fibres, which may be as a result of either hydrophobic or $\pi-\pi$ interactions or possibly both. 
(a)

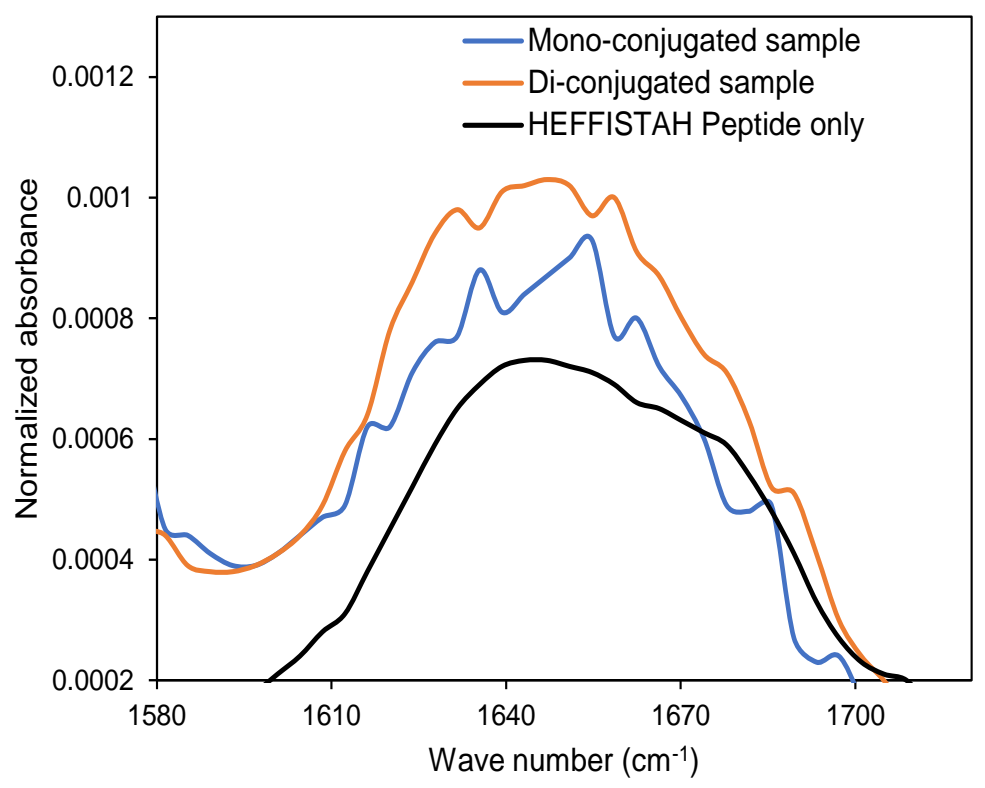

(c)

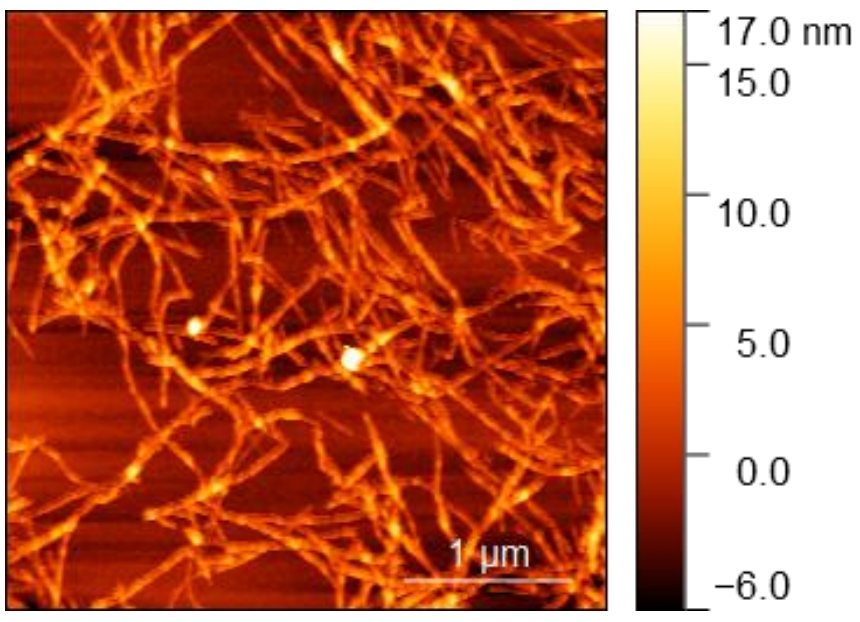

(b)

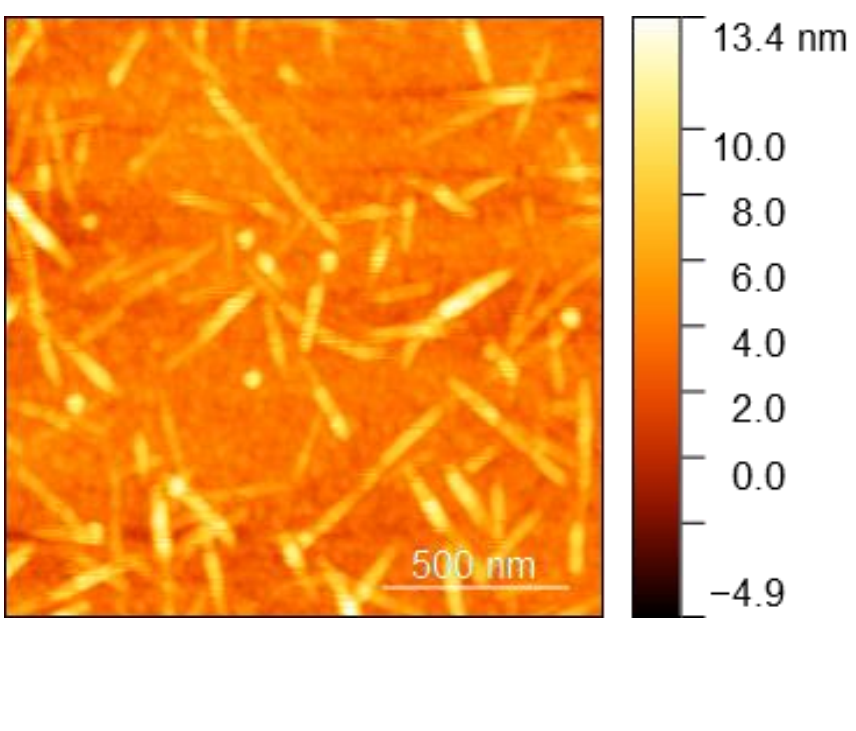

(d)

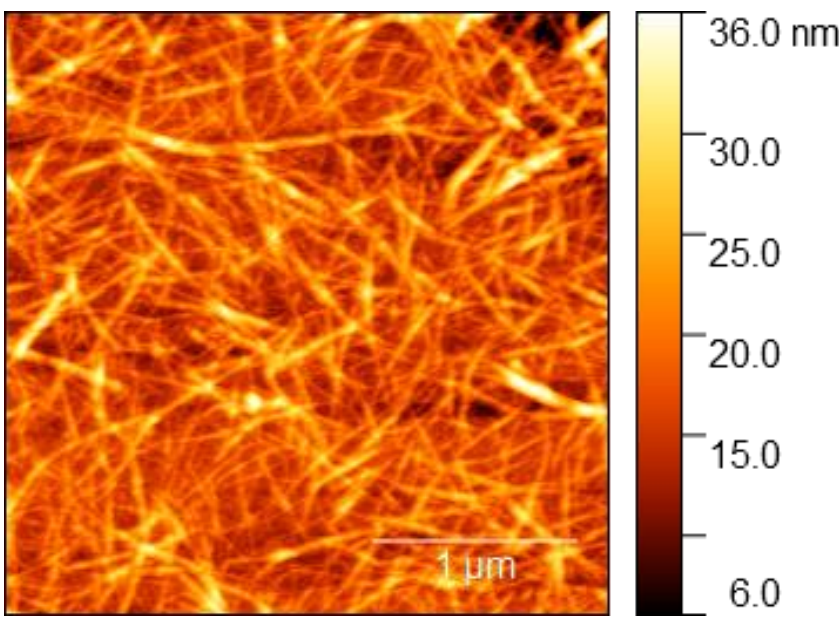

Figure 1: (a) FTIR spectrum of 1 wt. \% aqueous solution of un-conjugated HEFISTAH peptide, mono, and di-conjugated samples. AFM images of b) peptide (scale bar $=0.5 \mu \mathrm{m}$ ) (b) monoconjugated sample (scale bar $=1 \mu \mathrm{m}$ ) (c) di-conjugated sample (scale bar $=1 \mu \mathrm{m}$ ) prepared by drop-casting a $1 \mathrm{wt}$. \% solution of each of the samples onto freshly cleaved mica and followed by solvent evaporation in air. 
Figure 2 shows the surface pressure-area $(\Pi-A)$ isotherm of the unconjugated HEFISTAH peptide, mono, and di- conjugated samples. The peptide did not show any increase in surface pressure during compression when spread directly on a pure water subphase, thus indicating no surface activity: Figure 2. This phenomenon can be related to its high solubility. However, an increase in surface pressure was observed for the mono- and diconjugated samples upon compression indicating the formation of an insoluble monolayer at the interphase. The surface activity observed for the dye conjugated peptide samples can be attributed to the hydrophobicity of the TDPP dye. The change in slope observed during compression is indicative of a phase transition from a 2-D gaseous phase to a 2-D condensed phase. Extrapolation to $0 \mathrm{mN} / \mathrm{m}$ of the linear part, where the monolayer is assumed to be more compact, gives a limiting area/molecule of $\sim 22 \AA^{2}$ for the mono-and $\sim 34 \AA^{2}$ for the diconjugates respectively. These values are significantly lower than the theoretical areas, calculated as $133 \AA^{2}$ and $198 \AA^{2}$ for the mono- and di-conjugate sequence using $3.6 \AA$ as the average length of amino acid [30] and $37 \AA$ and $55 \AA$ as the estimated length of the TDPP in the mono- and di-conjugated samples respectively [29]. The result indicates that the peptide conjugate is not lying flat at the air-water interphase. 


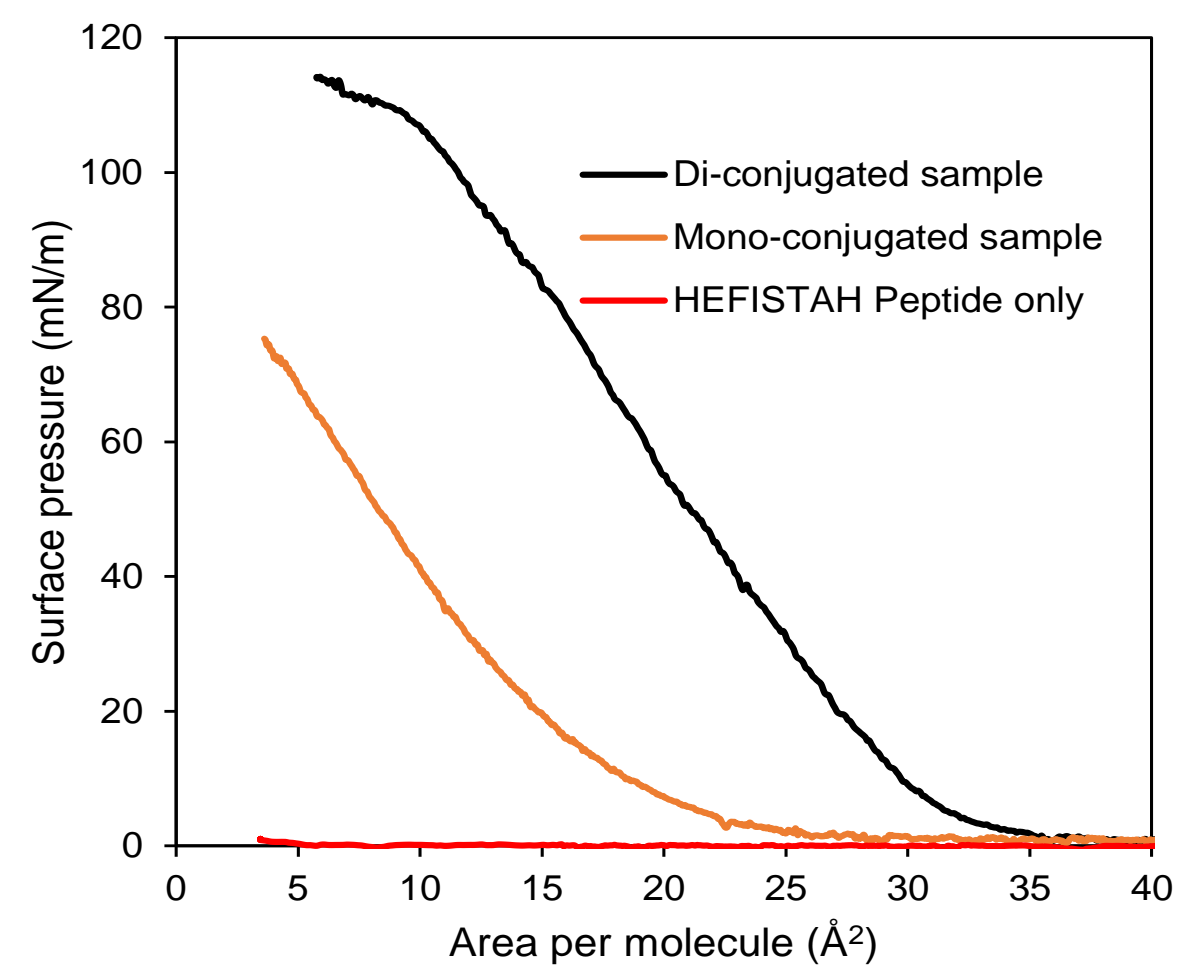

Figure 2: Surface pressure-area isotherm of Langmuir Blodgett film of HEFISTAH peptide, mono-conjugated and di-conjugated samples. Surface pressure is shown as the change from a base of $72.8 \mathrm{mN} \mathrm{m}^{-1}$. Area/molecule is the apparent area assuming that all the added samples are adsorbed at the interface.

Figure 3 shows the AFM images of the LB films transferred at constant pressures of $40 \mathrm{mN} / \mathrm{m}$ and $80 \mathrm{mN} / \mathrm{m}$ for the mono and di-conjugated samples respectively. The AFM image revealed closely packed fibres in the LB films of mono and di-conjugated samples, Figure $3(a-b)$ and Figure $3(c-d)$ respectively. The LB film of the di-conjugated sample, Figure 3 (c) showed long thin fibres that are well-aligned side by side. This indicates that the presence of two peptide units in the di-conjugated sample promoted the formation of longer fibres. This result also indicates that the peptide is a major contributor to fibre formation. The average height of the fibres in both films is about $0.3 \pm 0.4 \mathrm{~nm}$ which is close to the length of a single amino acid $(0.36 \mathrm{~nm})$, which may indicate that the peptide is aligned in a flat position at the interphase. Similarly, the fibre width is smaller than that observed for the drop cast films. 
(a)

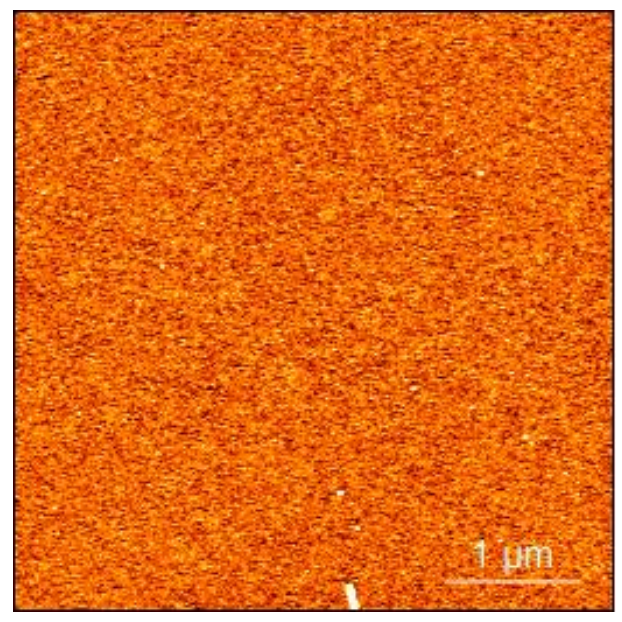

$1.8 \mathrm{~nm}$
-1.6
-1.4
-1.2
-1.0
-0.8
-0.6
-0.4
-0.0

(c)

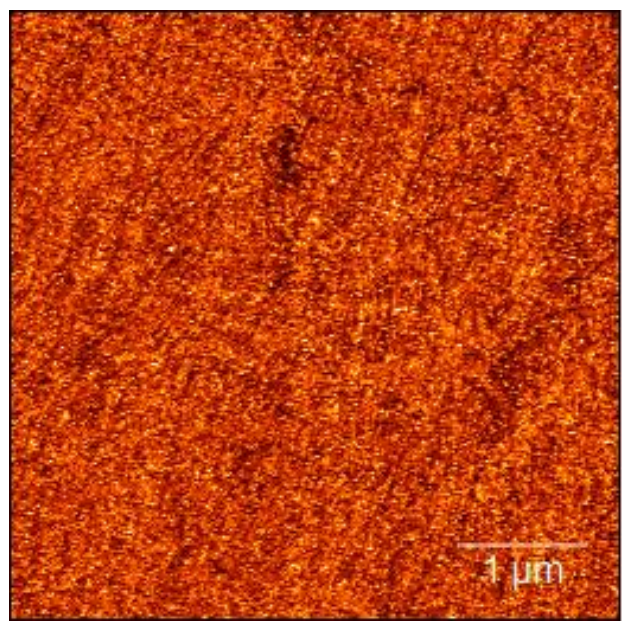

(b)

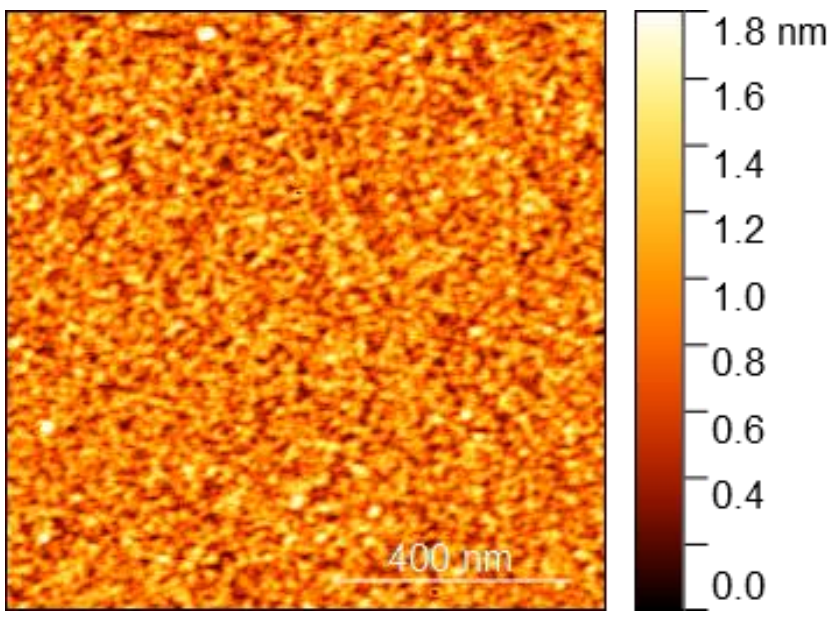

(d)

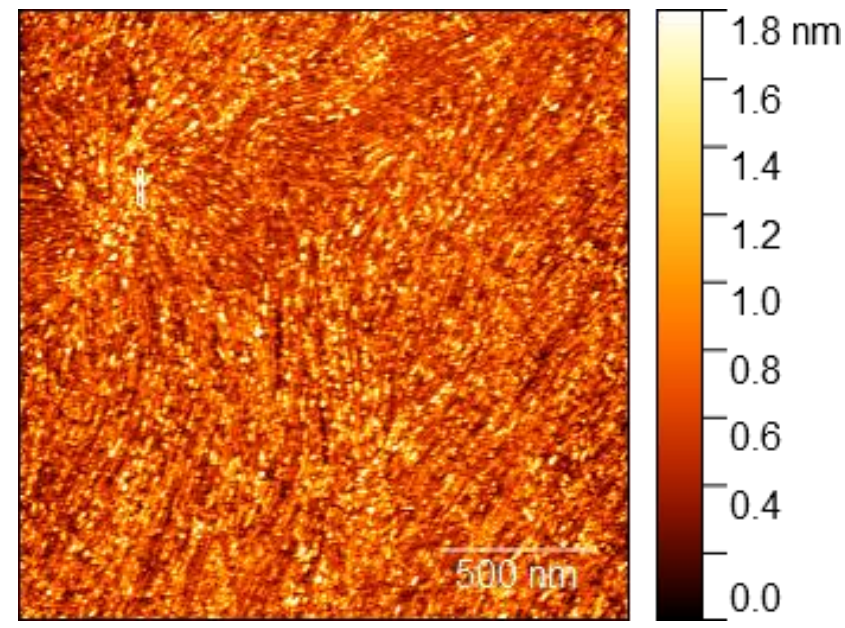

Figure 3: Atomic Force Microscopy (AFM) image of the resultant Langmuir Blodgett film of mono-conjugated sample (a) scale bar $=1 \mu \mathrm{m}$ (b) scale bar $=400 \mathrm{~nm}$ and di-conjugated sample (c) scale bar $=1 \mu \mathrm{m}$ (d) scale bar $=500 \mathrm{~nm}$.

The secondary structure of the LB films was investigated by FTIR. The FTIR spectrum, Figure 4 reveals an intense peak at $1627 \mathrm{~cm}^{-1}$ for the mono-conjugated sample and a similar intense peak at $1629 \mathrm{~cm}^{-1}$ for the di-conjugated sample. The observed intense peak at this band region indicates the presence of a predominantly $\beta$-sheet secondary structure in the LB films. The observed secondary structural confirmation is different from what was observed in the solution. It appears that the structural alignment at the interphase, because of compression of a monolayer, enhances $\beta$-sheet interaction. 


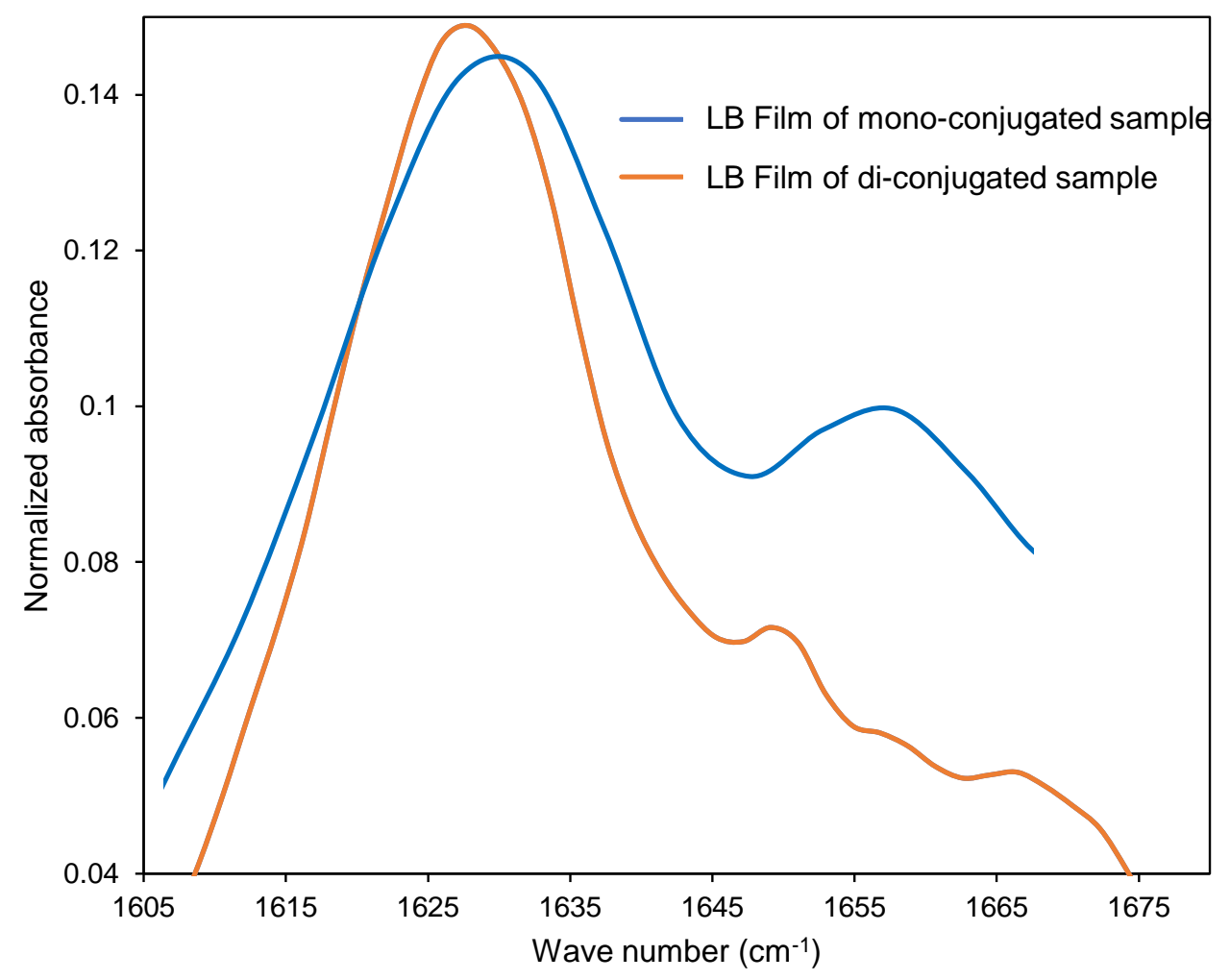

Figure 4: Result of FTIR of the Langmuir Blodgett film of the mono and di-conjugated samples transferred onto mica.

EIS was used to study the electronic properties of the nanofibers and the impedance data is presented as Nyquist plot, which is the plot of real impedance, $Z$ (resistive) against imaginary impedance $Z \mathbf{~}$ (capacitive) and as Bode plot which is a plot of frequency against the magnitude of the impedance $(/ Z /)$.

LB films formed on the interdigitated gold electrodes were of extremely high resistance (> $1 \mathrm{G} \Omega$ : figure $5(\mathrm{a})$ ). For the drop-cast films, measurable resistances could be achieved if the solution was aged for $24 \mathrm{hr}$ : in that case, thick, long fibres formed. If the aged solution was diluted then drop-cast, fibre networks could be formed of variable density depending on the dilution. Figure 5(c) shows an example. Figure 5 (a) and (b) shows Nyquist and Bode's plots comparing the EIS measurement of the di-conjugated sample films formed from the aged solution and LB film. Following these results, all mono and di conjugated sample films used for the EIS study were dropped cast from aged, concentrated solutions. 
(a)

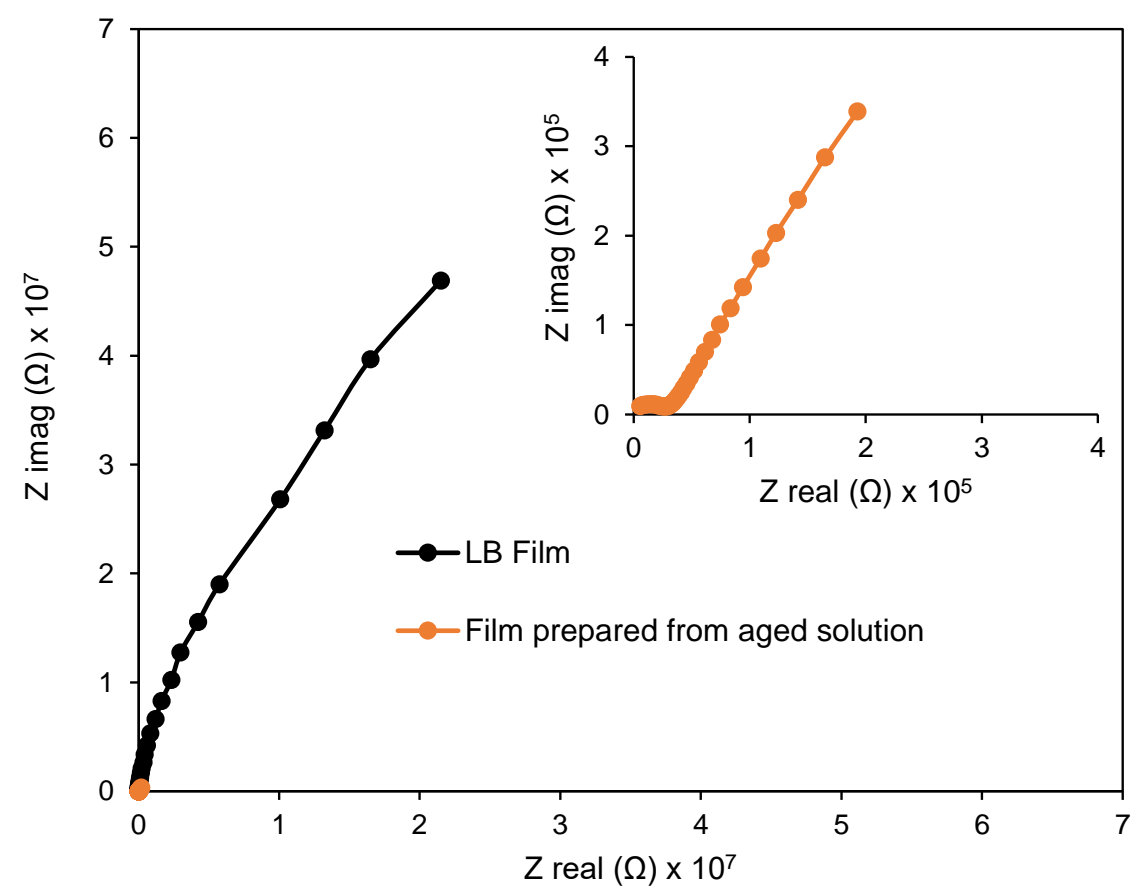

(b)

(c)
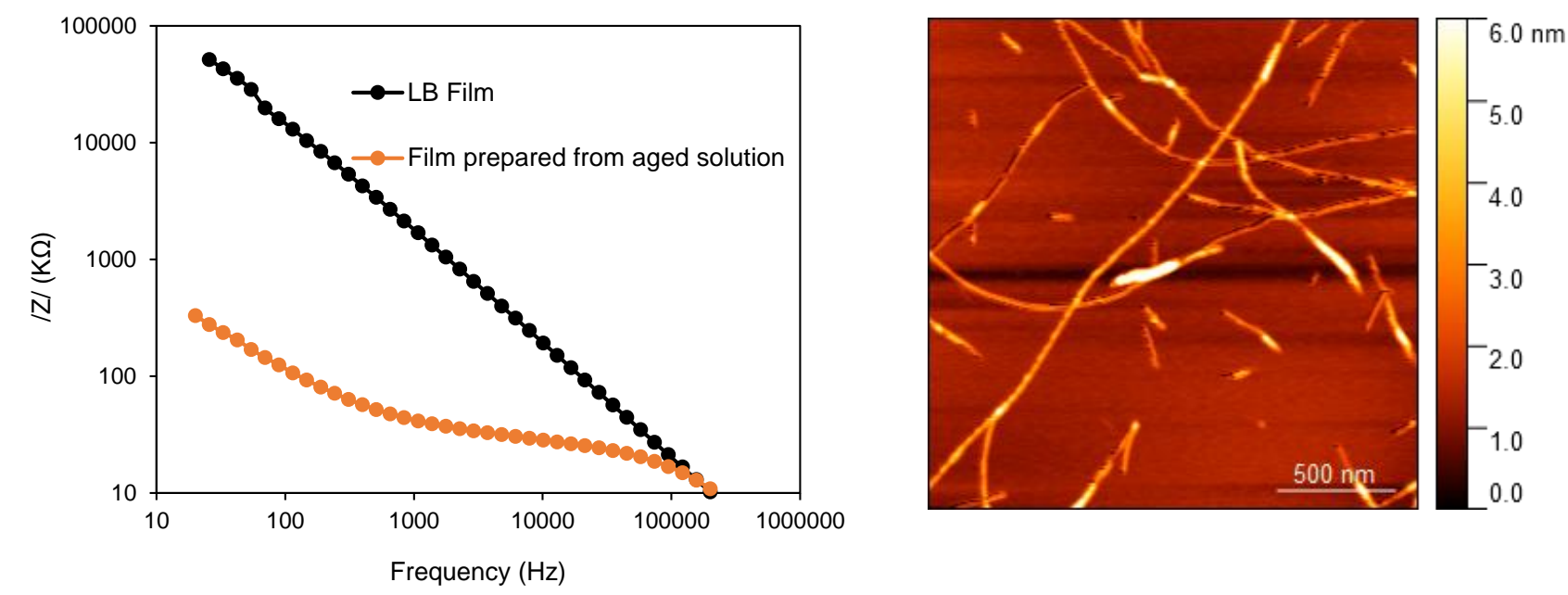

Figure 5: Result of the comparison of EIS measurements on LB films and films formed by drop-casting of $0.03 \mathrm{mg} / \mathrm{ml}$ solution diluted after $24 \mathrm{hrs}$ of ageing of a $1 \mathrm{wt} \%$ aqueous stock solution of the di-conjugated sample. (a) Nyquist plot (inset: Nyquist plot of the film formed from drop-casting the diluted aged solution), and (b) Bode plot. (c) AFM image of the diconjugated sample prepared by drop-casting the diluted, aged solution. The sample was prepared on a freshly cleaved mica and followed by solvent evaporation in air 
Figure 6 (a) compares the impedance of films formed on the interdigitated gold electrodes by drop-casting from $10 \mu \mathrm{L}$ of $0.03 \mathrm{mg} / \mathrm{ml}$ aged solutions of the mono-and di conjugated samples, and $10 \mu \mathrm{L}$ of $10 \mathrm{mg} / \mathrm{ml}$ HEFISTAH peptide solution. Peptide concentration used was significantly greater than that of the conjugates and this is because fibre formation was only observed at high concentrations $(10 \mathrm{mg} / \mathrm{ml})$ for the un-modified self-assembling peptide (HEFISTAH). Figure 6 (c) shows an equivalent circuit that represents the observed behaviour. The impedance was measured with a DC bias voltage of $0 \mathrm{~V}$. At $0 \mathrm{~V}$, there is no electrode reaction and no current flow. The electrode behaves as a capacitor but not an ideal capacitor and this can be attributed to the fibre connection with the electrodes. The equivalent circuit, therefore, relates to the morphology of the fibre network and the way it connects to the electrodes and it is interpreted based on these factors.

The series resistance element, $R$ obtained after fitting represents the resistance of the fibres within the network and it increases in the sequence di-conjugate $(26.7 \mathrm{k} \Omega)<$ mono-conjugate $(131.8 \mathrm{k} \Omega)<$ peptide $(1740 \mathrm{k} \Omega)$. The observed sequence is attributed to the fibre morphology as seen from the AFM image: a longer closely connected fibre network was observed for the di-conjugated samples compared to the mono-conjugated samples, with the un-conjugated peptide existing as short fibres and no evidence of long-extended fibre connection. The conjugates show, at low frequency, an element that approximates the impedance of the electrode and is represented as the constant phase element (CPE) in the circuit. The CPE has an impedance given by equation 1.0 [31]:

$$
Z(\omega)=\frac{1}{(j \omega)^{\alpha} C_{\alpha}}, 0<\alpha \leq 1
$$

Where $\omega$ is the angular frequency, $C_{\alpha}$ is the CPE parameter, $\alpha$ is the order which is usually between 0 and 1. An ordinary capacitor gives $\alpha=1$, a resistor gives $\alpha=0$ and $\alpha=0.5$ is used as a Warburg element usually used to model a diffusion process or infinite transmission line [31]. The order obtained hereafter fitting increases in the sequence, peptide $(0.29)<$ monoconjugate $(0.63)$ < di-conjugate (0.72). CPE behaviour can be explained physically in terms of electrode surface roughness, distribution of reaction rates, morphology, current distribution [32]. However, in this case, it appears to be related to the morphology and connectivity of the fibres. A highly smooth surface usually gives a CPE order of 1 , thus the farther away from 1 , the higher the degree of electrode roughness [32]. The non-connected short random fibres of the peptide randomly distributed on the electrode surface will lead to the formation of a more contorted electrode interface, hence the reason for the low CPE order of 0.29 . However, for the fibre networks that are closely connected on the electrode surface, this will appear as a 
more uniform or smooth electrode interface, hence the higher CPE order of 0.72 for the diconjugated sample and 0.63 for the mono-conjugated sample. The di-conjugated CPE with $\alpha=0.72$ is closer to being a typical capacitor, while the un-conjugated peptide CPE with $\alpha=$ 0.29 is closer to being a resistor compared to the other fibers.

The dependence of the electrical characteristics on the fibre network density of the diconjugated sample was also investigated. A scanning electron microscope was used to investigate the assembly of the long fibres across $10 \mu \mathrm{m}$ wide gold bands interdigitated with $10 \mu \mathrm{m}$ spacing. Aged $1 \mathrm{wt} \%$ solution of the di-conjugated sample diluted to $0.06 \mathrm{mg} / \mathrm{ml}$ and further diluted to $0.03 \mathrm{mg} / \mathrm{ml}$ and $0.015 \mathrm{mg} / \mathrm{ml}$ were used to demonstrate the effect of concentration on the fibre network density and morphology. At a higher concentration of 0.06 $\mathrm{mg} / \mathrm{ml}$, we observed both plaques and long rod-like structures with diameter on the $500 \mathrm{~nm}$ scale randomly placed across the electrode surface; higher magnification of the rod structures revealed the rods to comprise an assembly of smaller diameter fibres with also a sub-structure of smaller diameter fibres which formed a dense extended network. It appeared that, at this concentration, as the solution evaporated the network of fibres rolled up to form rod-like structures as well as plaques and blobs. At $0.03 \mathrm{mg} / \mathrm{ml}$, no rod-like structures were observed on the electrode surface: instead, the SEM revealed a nanofibre network mat lying on the electrode surface. At $0.015 \mathrm{mg} / \mathrm{ml}$, dispersed, long fibres were observed, Figure 6 (a) - (c). 


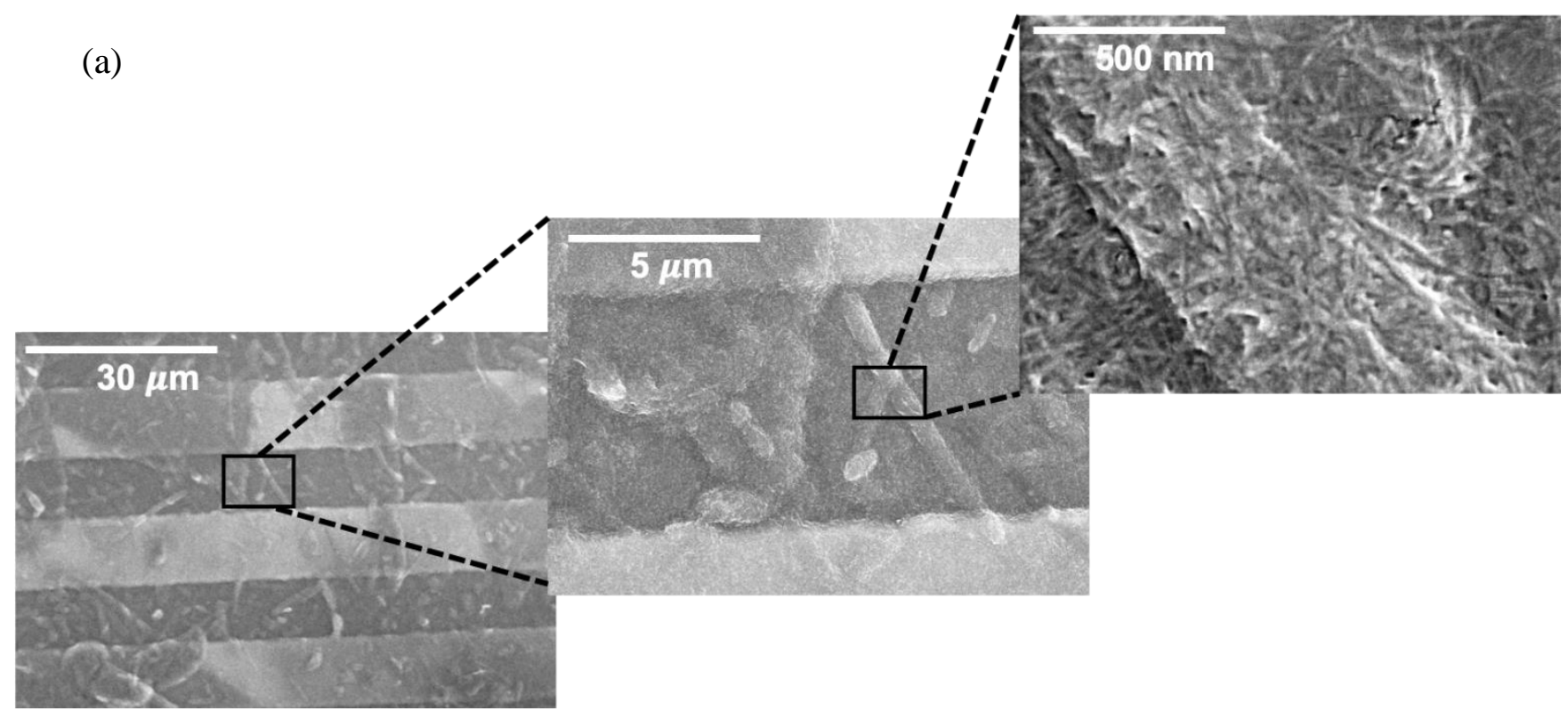

(b)

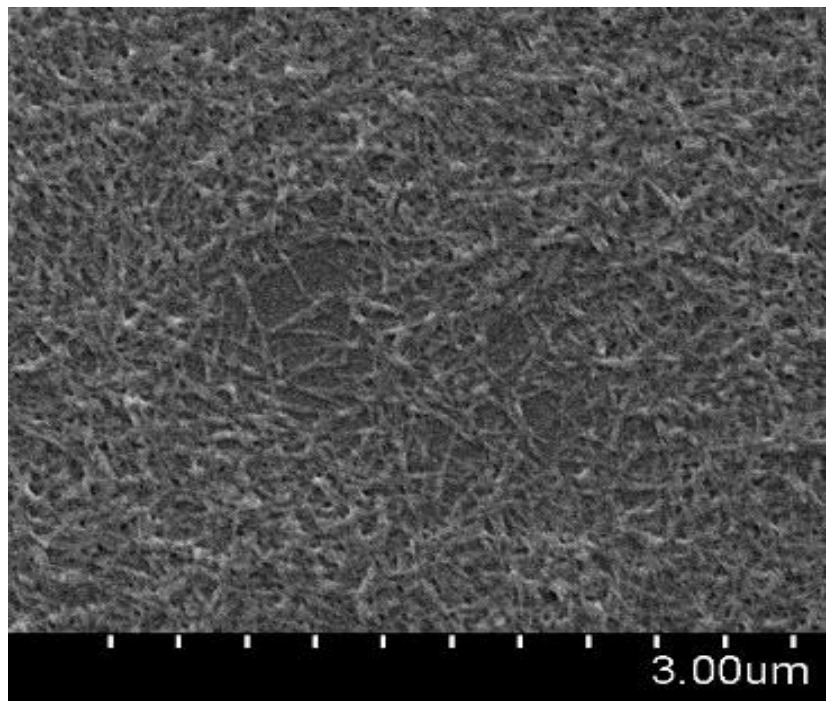

(c)

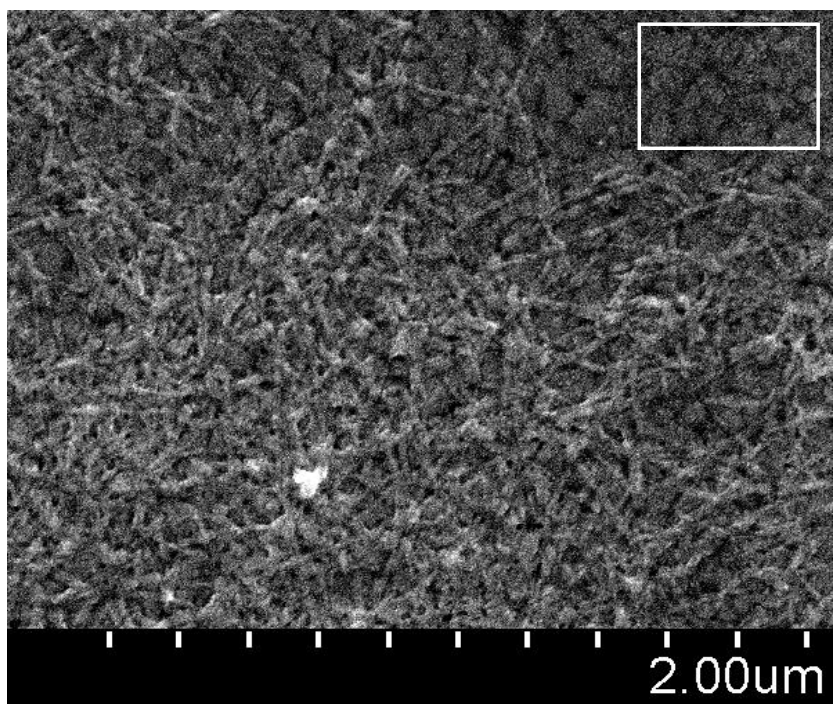

Figure 6: Scanning electron micrographs of the different concentrations of the di-conjugated nanofibres when deposited on the interdigitated electrode (a) $0.06 \mathrm{mg} / \mathrm{ml}$ (including higher magnification image) (b) $0.03 \mathrm{mg} / \mathrm{ml}$ (scale bar = $3 \mu \mathrm{m}$ ), (c) $0.015 \mathrm{mg} / \mathrm{ml}$ (scale bar $=2 \mu \mathrm{m}$ ). Samples were diluted from an aged stock solution, as described above. The granular substructure (highlighted in white box) is due to the gold film sputtered onto the surface of the electrode for imaging. 
In EIS measurements of the films, the series resistance element, Rs from the Nyquist plot was observed to increase in the sequence $0.06 \mathrm{mg} / \mathrm{ml}<0.03 \mathrm{mg} / \mathrm{ml}<0.015 \mathrm{mg} / \mathrm{ml}$, Figure 7 (a). From the Bode plot, we also observed at low frequency, an element that approximates a Warburg impedance - a transmission line-type element. This result indicates that close connection, which eventually, gives rise to more junctions within the network is essential for enhanced conductivity, with the more closed network showing the least resistance and the sparsely formed network showing the highest resistance.

(a)

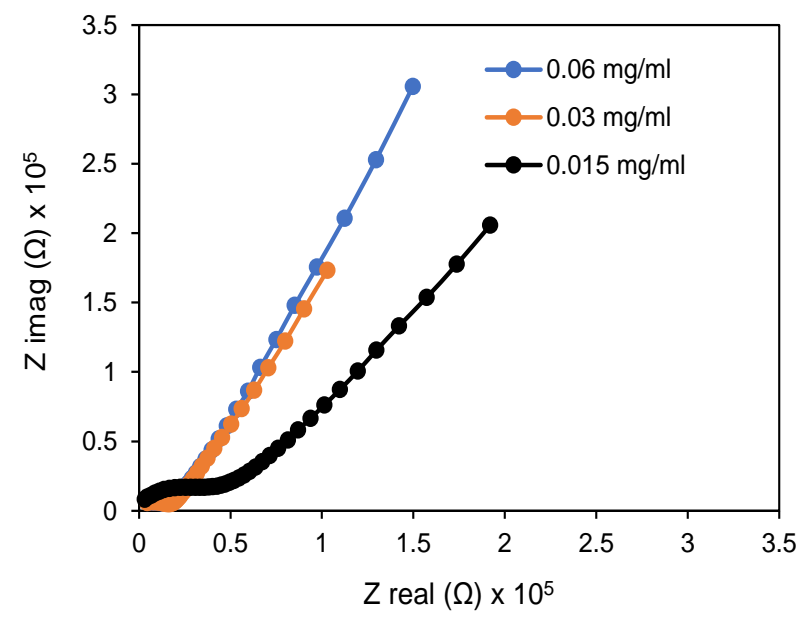

(b)

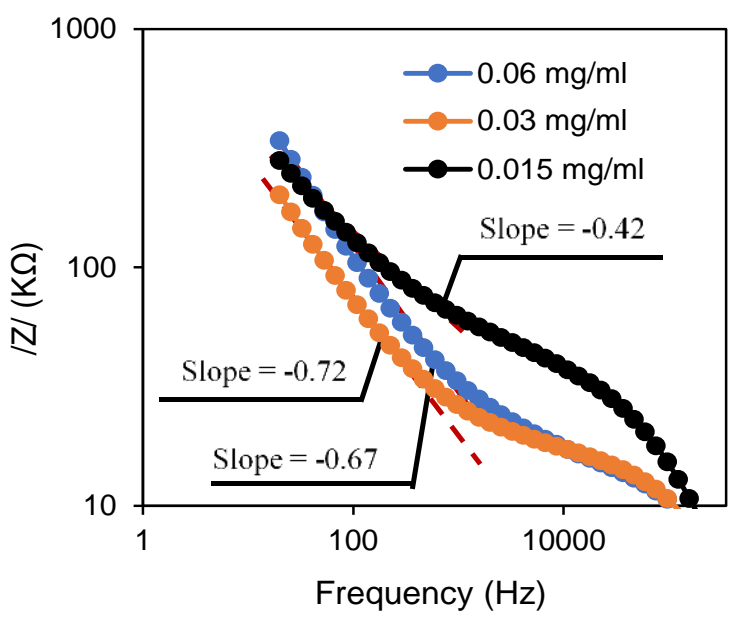

Figure 7: Dependence of electrical impedance on nanofibre network density (a) Nyquist plot and (b) Bode plot for nanofibres formed by drop-casting from varying concentrations of diconjugated sample, diluted from an aged solution. 
(a)

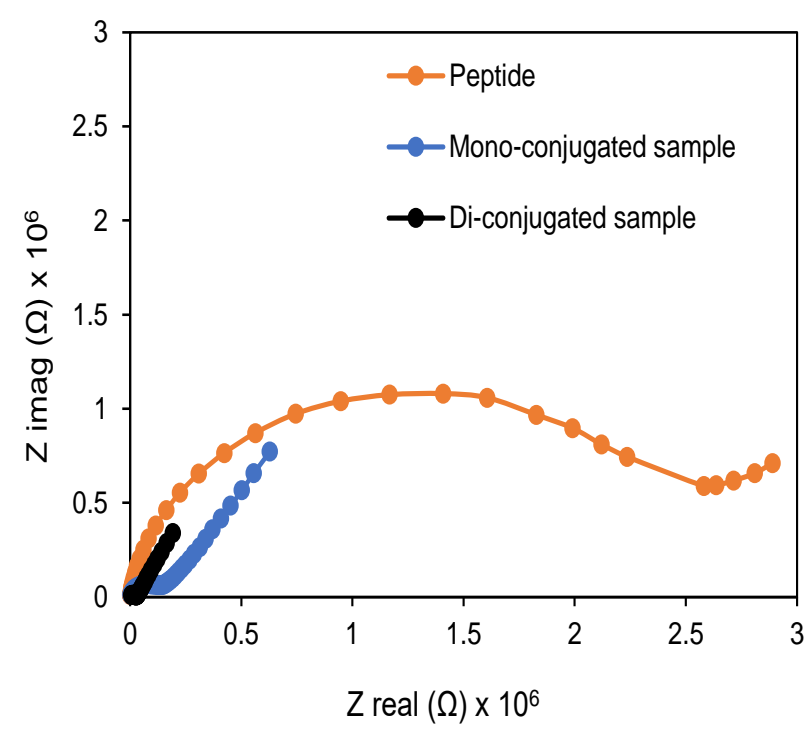

(b)

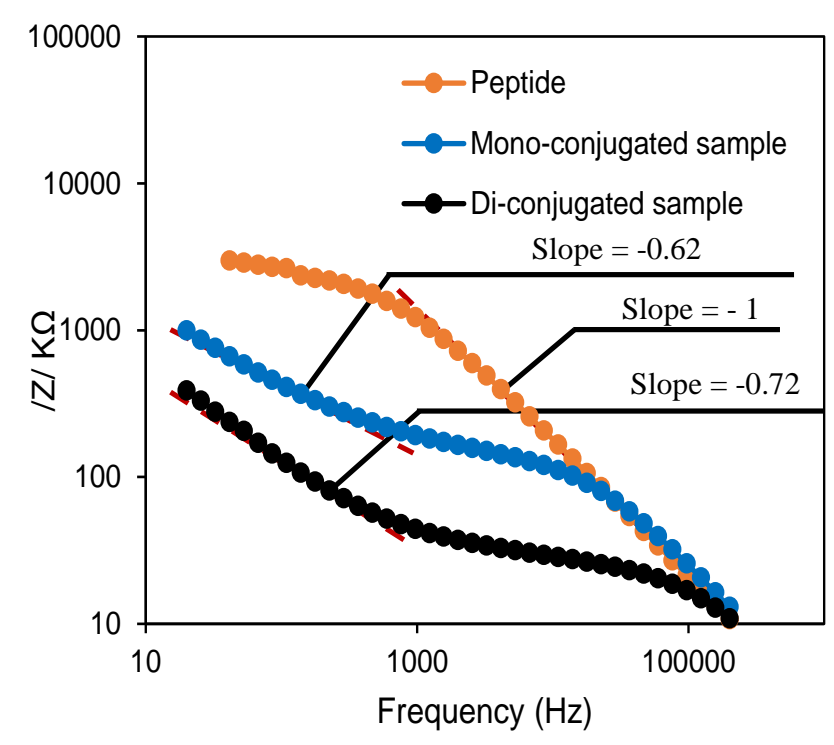

(c)

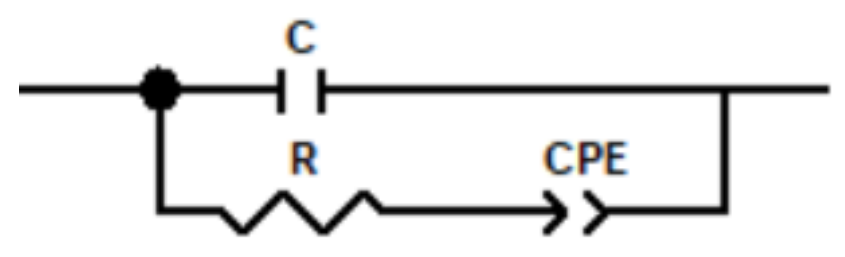

Figure 8: Result of EIS studies (a) Electrochemical impedance Nyquist plot and (b) Equivalent circuit model. (c) Bode plot of impedance magnitude for nanofibres formed from $10 \mathrm{mg} / \mathrm{ml}$ un-conjugated peptide solution and $1 \%$ aged then diluted to $0.03 \mathrm{mg} / \mathrm{ml}$, of mono and di-conjugated sample solutions deposited on a $10 \mu m \times 10 \mu m$ band interdigitated $\mathrm{Au}$ electrodes. On (c) the dashed lines show the limiting slopes for impedance. 
To understand the phenomena occurring on the electrode surface, the DC current-voltage dependence was investigated by imposing across the two electrode terminals a staircase potential difference between 0 and $2 \mathrm{~V}$ with a $20-\mathrm{mV}$ step, Figure 9 . The $10 \mu \mathrm{m}$ interdigitated gold electrode band modified by drop-casting $10 \mu \mathrm{L}$ of $0.03 \mathrm{mg} / \mathrm{ml}$ aged solution of the diconjugated sample was used for this experiment under varied atmosphere: ambient air ( $~ 58$ $\% \mathrm{RH}$ ), humidified nitrogen ( $98 \%-99 \% \mathrm{RH})$, vacuum ( $0 \% \mathrm{RH})$.

From the result, as shown in Figure 9 there was no observed evidence of electron transfer within the nanofibres nor evidence of interaction between the gold electrode and the nanofibre. However, what is seen is evidence of an electrode surface reaction that is consistent with an oxygen reduction reaction (ORR). ORR on gold is a complicated system that is strongly dependent on $\mathrm{pH}$ [33]. The waves (I, II, and III) observed are consistent with an oxygen reduction reaction that is limited by the diffusion of oxygen [34-37].

A significant drop in the current (I) was observed from the measurement in sequence: I (ambient room air) $\Longrightarrow I$ (humidified Nitrogen) $\Longrightarrow I$ (vacuum). This can be associated with the significant drop in oxygen levels in the system. Humidified nitrogen atmosphere has a significantly low residual oxygen, but not as low as the vacuum atmosphere as indicated by the current. The significant drop in the oxygen diffusion peak at the higher potential for humidified nitrogen is consistent with a low-oxygen atmosphere.

The ability of the nanofibre network to allow the Faradaic process to occur at the electrode surface confirms the conducting properties of the di-conjugated nanofibre network. However, the understanding is that for the oxygen reduction reaction to occur, it requires an electrolyte to facilitate the reduction process. With this regard, in the subsequent experiment, the underlying conduction mechanism facilitating the ORR was explored. 

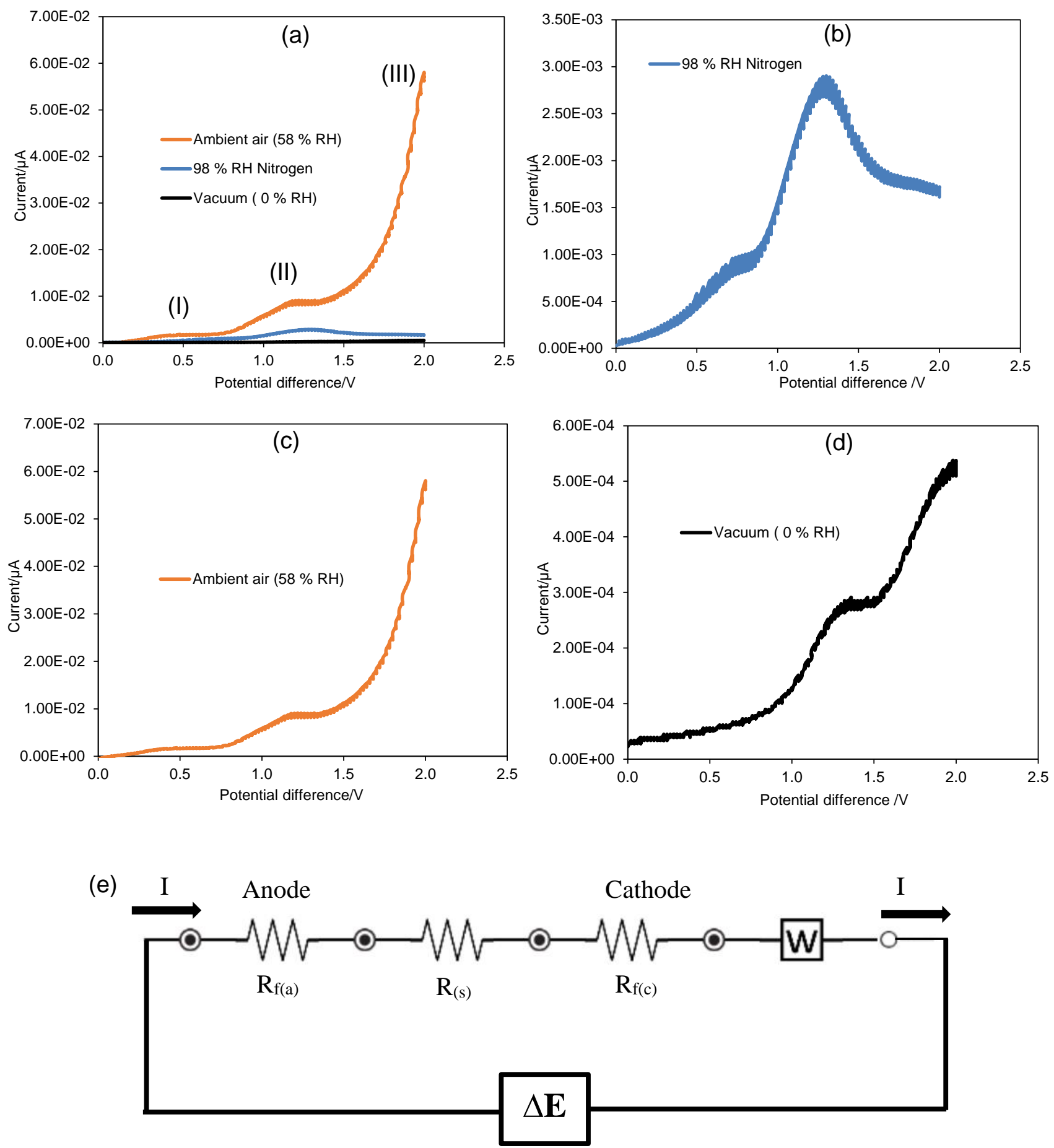

Figure 9: Current-voltage (I-V) characteristics of di-conjugated sample nanofibre network under (a) All 3 varied atmosphere (b) $98 \%$ RH Nitrogen (c) Ambient room air ( $58 \% R H$ ) (d) Vacuum ( $0 \% R H$ ) atmospheric conditions, (e) Representation of the DC current-voltage experiment. Potential difference is passed across the two terminals: anode and cathode generating current from the anode through the resistor (solution, $R_{s}$ ) to the cathode. Based on the waves observed in the IV curve, it is evident that electrode reactions occur (anode represented $R_{f(a)}$ and cathode by $\left.R_{f(b)}\right)$ where at least one is limited by diffusion of oxygen. 
To understand the underlying mechanism of conductivity in the 3 nanofibers deposited on the electrodes, particularly understanding of the conductivity as a consequence of an electron or proton transfer within the networks, EIS measurements of the networks were investigated under $\sim 0 \% \mathrm{RH}$ atmospheric condition. The Nyquist plot for the 3 networks appears as a vertical line which is typical of a pure capacitor indicating that at $0 \% \mathrm{RH}$, no conductivity was observed in the 3 networks. The Bode plot also reveals very high values of the impedance magnitude. The slope -1 on the Bode plot confirms the pure capacitive behaviour. All three networks were identical (ESI 4).

At a higher relative humidity of 98 - $99 \%$, a decrease in resistance was observed including under air and nitrogen atmospheric conditions. The nitrogen and air conditions were humidified to $\sim 98-99 \% \mathrm{RH}$ and a lower resistance were observed within the networks. However, under dry nitrogen and air conditions, the Nyquist plot appears as a vertical line similar to that which was observed at $\sim 0 \% \mathrm{RH}$, indicating that in the absence of water, the di and mono conjugated sample fibre network behaves like a pure capacitor. Similarly, the Bode plot of the magnitude of the impedance shows a very high impedance magnitude at low frequency and a linear behaviour from the high to low frequency; behaviour which is typical of a pure capacitor (ESI 4).

This behaviour under nitrogen and air atmospheric conditions confirm the strong dependence of the conductance of nanofibres on relative humidity. Such behaviour has been reported for proteins [38-41], peptides [42-46], synthetic polymers [47], DNA [48-51], and oxides [52], and in all cases, they have been attributed to protonic conductivity. Figure 10 shows the comparison Bode plot of the nanofibres formed from the di-conjugated sample under all varied atmospheric conditions. 


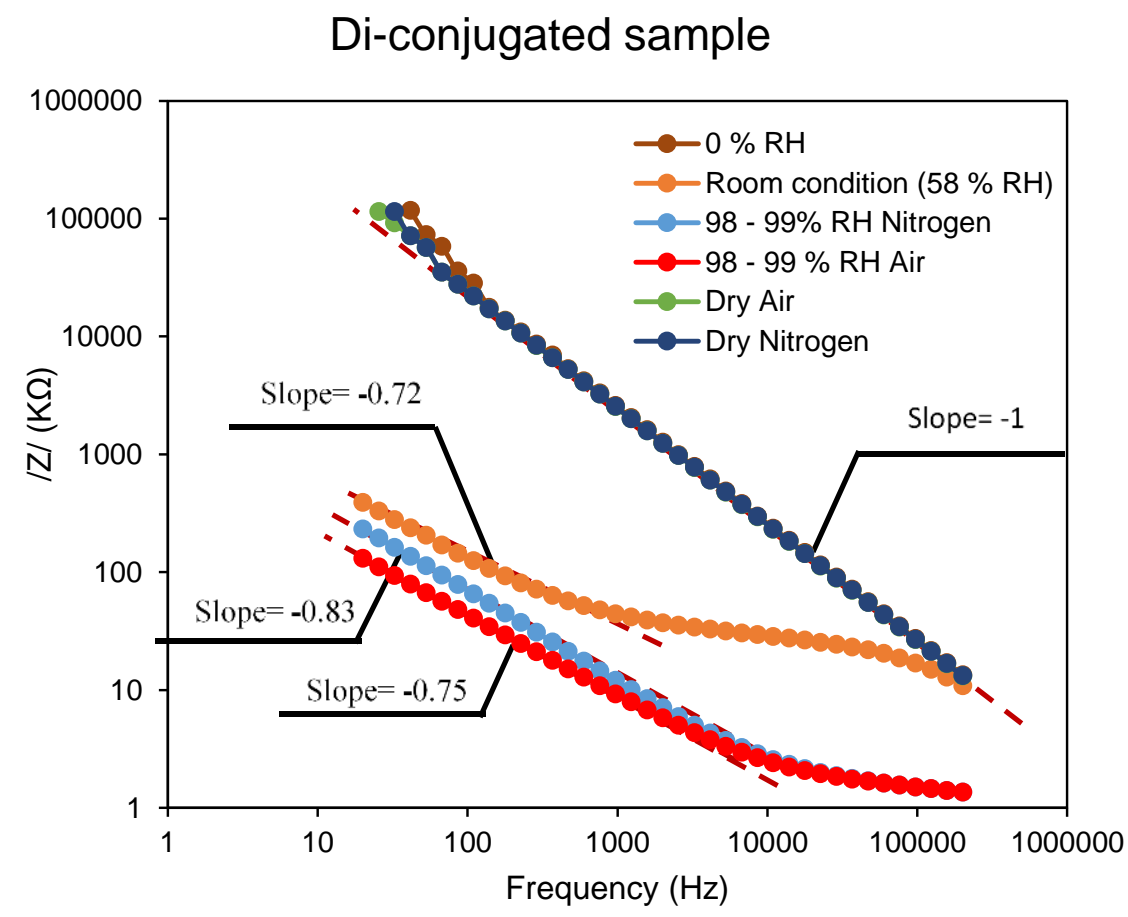

Figure 10: A comparative Bode plot of the di-conjugated sample under all atmospheric conditions investigated. The dashed lines show the limiting slopes for impedance.

Proton conductivity is greatly affected by the presence of water and this is because water induces the protonation processes allowing protons to be transferred from the organic scaffold to a water molecule forming an $\mathrm{H}_{3} \mathrm{O}^{+}$ion or vice-versa resulting in the formation of solvated $\mathrm{OH}^{-}$ions. Both processes can result in a protonic-type charge transfer within a system.

The conductivity observed in the un-conjugated peptide network indicates that the proton conductivity can be found for the peptide alone. However, the enhanced conductivity observed in the peptide-dye monomer network indicates that the dye with the $\pi$-conjugated system enhances the proton transfer over a longer range through self-assembly. Similarly, the further enhanced conductivity observed from the di-conjugated nanofibre network is because of an increase in proton available for transfer within the system. This is a consequence of the presence of two peptide units in the di-conjugated nanofibre network providing more protons compared to the monomer with one peptide unit. The peptide sequence (HEFISTAH) contains an amino acid (glutamic acid) with a carboxylic side chain that can undergo deprotonation contributing a proton $\left(\mathrm{H}^{+}\right)$to the proton-conduction channels. Ohad et al. [53] reported a significant increase in conductivity in a peptide sequence just by replacing lysine with glutamic acid and they attributed this phenomenon to the ability of the carboxylic acid to contribute protons into the proton-channel system. 


\section{Conclusion}

The formation of long-range 2D assemblies of a new class of bio-organic material comprising a nature-inspired self-assembling peptide and an organic semiconducting molecule TDPP has been explored. It was demonstrated that through compression of the peptide monolayer at the air-water interphase, strong interaction can be enhanced persuading $\beta$-sheet interaction between the peptide fibres allowing for the formation of well-aligned long nanofibres. Using electrochemical impedance spectroscopy, the electrical conductivity in the nanofibres formed from the un-conjugated peptide and the mono and di-conjugated samples were also studied. Higher conductivity in the di-conjugated nanofibres compared to mono-conjugated and unconjugated peptide fibres was observed and an increase in conductivity with increasing nanofibre network density was also observed. We attribute the conductivity observed in the nanofibres to the peptide containing an ionisable side chain, which becomes enhanced as a consequence of assembly promoted by the $\pi-\pi$ interaction of the TDPP dye. The strong dependence of the electrical conductivity of the nanofibres on relative humidity confirms proton conductivity as the mechanism of electrical conductivity in the nanofibre network. DC currentvoltage measurements also do not show any evidence of electronic transfer within the nanofibre network, but evidence of surface reaction that is dependent on oxygen level and atmospheric moisture that acts as the electrolyte was seen. This study has thus expanded the scope for the design of new classes of peptide-based hybrid materials as proton conductors.

\section{Acknowledgments}

The authors thank The MacDiarmid Institute for Advanced Materials and Nanotechnology, New Zealand for providing a Ph.D. Scholarship and funding. 


\section{References}

1. Tao, K., et al., Self-assembling peptide semiconductors. Science, 2017. 358(6365).

2. Adler-Abramovich, L. and E. Gazit, The physical properties of supramolecular peptide assemblies: from building block association to technological applications. Chemical Society Reviews, 2014. 43(20): p. 6881-6893.

3. Rapaport, H., Ordered peptide assemblies at interfaces. Supramolecular Chemistry, 2006. 18(5): p. 445-454.

4. Wang, J., et al., Peptide self-assembly: thermodynamics and kinetics. Chemical Society Reviews, 2016. 45(20): p. 5589-5604.

5. Gopalan, R.D., et al., Geometrically Precise Building Blocks: the Self-Assembly of beta-Peptides. Chemistry \& Biology, 2015. 22(11): p. 1417-1423.

6. Leshem, A., S. Zarzhitsky, and H. Rapaport, Functional Peptide Monolayers at Interfaces. Israel Journal of Chemistry, 2015. 55(6-7): p. 661-670.

7. Versluis, F., H.R. Marsden, and A. Kros, Power struggles in peptide-amphiphile nanostructures. Chemical Society Reviews, 2010. 39(9): p. 3434-3444.

8. Krieg, E., et al., Supramolecular polymers in aqueous media. Chemical reviews, 2016. 116(4): p. 2414-2477.

9. Pan, W. and T. Chunyan, Biological Sensing and Imaging Using Conjugated Polymers and Peptide Substrates. Protein \& Peptide Letters, 2021. 28(1): p. 2-10.

10. Krishna, O.D. and K.L. Kiick, Protein- and peptide-modified synthetic polymeric biomaterials. Biopolymers, 2010. 94(1): p. 32-48.

11. Shu, J.Y., B. Panganiban, and T. Xu, Peptide-Polymer Conjugates: From Fundamental Science to Application. Annual Review of Physical Chemistry, 2013. 64(1): p. 631-657.

12. Wu, W., G.C. Bazan, and B. Liu, Conjugated-Polymer-Amplified Sensing, Imaging, and Therapy. Chem, 2017. 2(6): p. 760-790.

13. McQuade, D.T., A.E. Pullen, and T.M. Swager, Conjugated Polymer-Based Chemical Sensors. Chemical Reviews, 2000. 100(7): p. 2537-2574.

14. He, R., et al., Peptide Conjugates with Small Molecules Designed to Enhance Efficacy and Safety. Molecules (Basel, Switzerland), 2019. 24(10): p. 1855.

15. Hoppenz, P., S. Els-Heindl, and A.G. Beck-Sickinger, Peptide-Drug Conjugates and Their Targets in Advanced Cancer Therapies. Frontiers in Chemistry, 2020. 8(571).

16. Chandran, D. and K. Lee, Diketopyrrolopyrrole: $A$ versatile building block for organic photovoltaic materials. Macromolecular Research, 2013. 21: p. 272-283.

17. Kaur, M. and D.H. Choi, Diketopyrrolopyrrole: brilliant red pigment dye-based fluorescent probes and their applications. Chemical Society Reviews, 2015. 44(1): p. 58-77. 
18. Zhou, E., et al., Synthesis and Photovoltaic Properties of Diketopyrrolopyrrole-Based Donor-Acceptor Copolymers. Chemistry of Materials, 2009. 21(17): p. 4055-4061.

19. Chen, $\mathrm{H}$., et al., Highly $\pi$-extended copolymers with diketopyrrolopyrrole moieties for high-performance field-effect transistors. Adv Mater, 2012. 24(34): p. 4618-22.

20. Kanimozhi, C., et al., Diketopyrrolopyrrole-Diketopyrrolopyrrole-Based Conjugated Copolymer for High-Mobility Organic Field-Effect Transistors. Journal of the American Chemical Society, 2012. 134(40): p. 16532-16535.

21. Langhals, H., et al., The Influence of Packing Effects on the Solid-State Fluorescence of Diketopyrrolopyrroles. Angewandte Chemie International Edition in English, 1989. 28(4): p. 478-480.

22. Li, Z., et al., Alkyl Side Chain Impact on the Charge Transport and Photovoltaic Properties of Benzodithiophene and Diketopyrrolopyrrole-Based Copolymers. The Journal of Physical Chemistry C, 2011. 115(36): p. 18002-18009.

23. Grzybowski, M. and D.T. Gryko, Diketopyrrolopyrroles: Synthesis, Reactivity, and Optical Properties. Advanced Optical Materials, 2015. 3(3): p. 280-320.

24. Niu, W., et al., Synthesis and Properties of Soluble Fused Thiophene Diketopyrrolopyrrole-Based Polymers with Tunable Molecular Weight. Macromolecules, 2018. 51(23): p. 9422-9429.

25. Bronstein, H., et al., Thieno[3,2-b]thiophene-diketopyrrolopyrrole Containing Polymers for Inverted Solar Cells Devices with High Short Circuit Currents. Advanced Functional Materials, 2013. 23(45): p. 5647-5654.

26. Draper, E.R., B. Dietrich, and D.J. Adams, Self-assembly, self-sorting, and electronic properties of a diketopyrrolopyrrole hydrogelator. Chemical Communications, 2017. 53(11): p. 1864-1867.

27. Eakins, G.L., et al., Functional Organic Semiconductors Assembled via Natural Aggregating Peptides. Advanced Functional Materials, 2015. 25(35): p. 5640-5649.

28. Rani, A., Synthesis and Self Assembling Properties of Peptide-Based Hydrogels, in School of Chemical Sciences. 2020, The University of Auckland. p. 254.

29. Rani, A., et al., Directed self-assembly of peptide-diketopyrrolopyrrole conjugates - a platform for bio-organic thin film preparation. Soft Matter, 2020. 16(28): p. 6563-6571.

30. Ainavarapu, S.R., et al., Contour length and refolding rate of a small protein controlled by engineered disulfide bonds. Biophys J, 2007. 92(1): p. 225-33.

31. Holm, S., T. Holm, and Ø.G. Martinsen, Simple circuit equivalents for the constant phase element. PLoS ONE, 2021. 16(3): p. e0248786.

32. Rodgers, R.S., The Constant Phase Element, in Electrochemical Resources. 2014. 
33. Damjanovic, A., M.A. Genshaw, and J.O.M. Bockris, Hydrogen peroxide formation in oxygen reduction at gold electrodes: II. Alkaline solution. Journal of Electroanalytical Chemistry and Interfacial Electrochemistry, 1967. 15: p. 173-180.

34. Jeyabharathi, C., et al., Oxygen electroreduction on polycrystalline gold electrodes and on gold nanoparticle-modified glassy carbon electrodes. Journal of Solid State Electrochemistry, 2014. 18(12): p. 3299-3306.

35. Vassilev, P. and M.T.M. Koper, Electrochemical Reduction of Oxygen on Gold Surfaces: A Density Functional Theory Study of Intermediates and Reaction Paths. The Journal of Physical Chemistry C, 2007. 111(6): p. 2607-2613.

36. Kim, J. and A.A. Gewirth, Mechanism of Oxygen Electroreduction on Gold Surfaces in Basic Media. The Journal of Physical Chemistry B, 2006. 110(6): p. 2565-2571.

37. Burke, L. and P. Nugent, The electrochemistry of gold: I the redox behaviour of the metal in aqueous media. Gold Bulletin, 1997. 30: p. 43-53.

38. Pompa, P.P., et al., Charge transport in disordered films of non-redox proteins. The Journal of Chemical Physics, 2006. 125(2): p. 021103.

39. Rosenberg, B., Electrical Conductivity of Proteins. II. Semiconduction in Crystalline Bovine Hemoglobin. The Journal of Chemical Physics, 1962. 36(3): p. 816-823.

40. Bardelmeyer, G.H., Electrical conduction in hydrated collagen. I. Conductivity mechanisms. Biopolymers, 1973. 12(10): p. 2289-302.

41. Morgan, H. and R. Pethig, Protonic and ionic conduction in lysozyme. Hydration and field-dependent effects. Journal of the Chemical Society, Faraday Transactions 1: Physical Chemistry in Condensed Phases, 1986. 82(1): p. 143-156.

42. Song, M.-K., et al., Proton-enabled activation of peptide materials for biological bimodal memory. Nature Communications, 2020. 11(1): p. 5896.

43. Sung, T., et al., Effects of proton conduction on dielectric properties of peptides. RSC Advances, 2018. 8(59): p. 34047-34055.

44. Amit, M., et al., Hybrid Proton and Electron Transport in Peptide Fibrils. Advanced Functional Materials, 2014. 24(37): p. 5873-5880.

45. Silberbush, O., et al., Self-Assembled Peptide Nanotube Films with High Proton Conductivity. The Journal of Physical Chemistry B, 2019. 123(46): p. 9882-9888.

46. Lerner Yardeni, J., et al., Sequence dependent proton conduction in self-assembled peptide nanostructures. Nanoscale, 2016. 8(4): p. 2358-2366.

47. Christie, J.H., S.H. Krenek, and I.M. Woodhead, The electrical properties of hygroscopic solids. Biosystems Engineering, 2009. 102(2): p. 143-152.

48. Han Ha, D., et al., Humidity effects on the conductance of the assembly of DNA molecules. Chemical Physics Letters, 2002. 355(5): p. 405-409. 
49. Yamahata, C., et al., Humidity dependence of charge transport through DNA revealed by silicon-based nanotweezers manipulation. Biophys J, 2008. 94(1): p. 63-70.

50. Vedala, $\mathrm{H}$., et al., The effect of environmental factors on the electrical conductivity of a single oligo-DNA molecule measured using single-walled carbon nanotube nanoelectrodes. Nanotechnology, 2008. 19(26): p. 265704.

51. Skinner, B., M.S. Loth, and B.I. Shklovksii, lonic conductivity on a wetting surface. Physical Review E, 2009. 80(4): p. 041925.

52. Anderson, J.H. and G.A. Parks, Electrical conductivity of silica gel in the presence of adsorbed water. The Journal of Physical Chemistry, 1968. 72(10): p. 3662-3668.

53. Silberbush, O., et al., Significant Enhancement of Proton Transport in Bioinspired Peptide Fibrils by Single Acidic or Basic Amino Acid Mutation. Advanced Functional Materials, 2017. 27(8): p. 1604624. 